

\section{“... Para ser macho não pode negar fogo, tem que ser viril. Então não tem nada a ver com a dança..." 1}

\begin{abstract}
RESUMO: Este empreendimento se propõe a analisar a percepção de alunos de graduação em Educação Física sobre construção sociocultural do corpo masculino. Com o propósito de colher informações, empreendemos um estudo inserido no paradigma fenomenológico-hermenêutico, utilizando análise de discurso e envolvendo 27 alunos de ambos os sexos do curso de graduação em Educação Física das diversas universidades do Rio de Janeiro. Os instrumentos empregados constaram de uma entrevista semi-estruturada e da exibição de uma foto, na qual bailarinos do sexo masculino pousavam com tutu (vestimenta tradicionalmente utilizada pelo sexo feminino). Incursionando nas respostas dos entrevistados, identificamos 6 elementos marcantes: 1- o símbolo da vestimenta; 2- as atividades ditas femininas; 3- o futebol; 4- "Outros"; 5- a homossexualidade e; 6- raça e gênero.
\end{abstract}

PALAVRAS-CHAVE: gênero, corpo e educação física.

\section{Pra início de conversa...}

As questões relativas a gênero começaram a ser estudadas com a devida profundidade a partir da década de 70, logo, podemos concluir que se trata de um assunto recente no que diz respeito à sua historicidade e a seus estudos científicos. Desde este período, muitos pesquisadores tendem a confundir sexo com gênero. Neste caso, nosso estudo se resguarda de possíveis confusões conceituais e procura uma adequada definição para a categoria gênero apoiada na concepção de Scott (1995, p.75), que assim define:

[...] o termo "gênero" também é utilizado para designar as relações sociais entre os sexos. Seu uso rejeita explicitamente explicações biológicas, [...]. O termo "gênero" torna-se uma forma de indicar "construções culturais" a criação inteiramente social de idéias sobre os papéis adequados aos homens e às mulheres [...]. Gênero é, segundo esta definição, uma categoria social imposta sobre um corpo sexuado. [...] o gênero tornou-se uma

\section{Erik Giusepp}

Mestre em Ciência da Motricidade Humana UCB/RJ Professor da Universidade Estácio de Sá/RJ; Universidade Salgado de Oliveira/ Niterói-RJ egiuseppe@ig.com.br

\section{Elaine Romero}

Doutora com Pós-doutorado em Ciências na USP/SP

Professora Titular do Curso de Pós-Graduação em Ciência da Motricidade Humana da UCB/R eromero@castelobranco.br

(1) Este estudo é parte integrante do trabalho dissertativo defendido no Programa de Pós-Graduacão Stricto Sensu em Ciência da Motricidade Humana da UCB/RJ e cujo título foi inspirado em um dos discursos proclamados por um dos atores sociais da pesquisa. 
palavra particularmente útil, pois oferece um meio de distinguir a prática sexual dos papéis sexuais atribuídos às mulheres e aos homens.

Resgatando a trajetória histórica acerca dos trabalhos que deram os primeiros e grandes passos na questão do gênero masculino, podemos verificar que o interesse pela masculinidade como campo de estudo teve origem na década de 1960, mais precisamente a partir da organização do movimento feminista que promoveu um exame crítico e tomada de posição diante das desigualdades sociais baseadas nas diferenças sexuais (CUNHA JÚNIOR, 2000, p. 397). Esse fato nos revela, então, que os estudos do gênero masculino na esfera da cultura corporal de movimento podem ser assim ressaltados: em nível internacional, os estudos de Messner e Sabo (1990) e de Macdonald (1995); e em nível nacional, como os de Guedes (1977, 1992 e 1998) e de Cunha Júnior (op.cit.). Revisando estas literaturas, constatamos que quase nada se encontrou, mais efetivamente, até o presente momento a respeito da questão de gênero nas aulas de educação física e sua contribuição na construção do corpo masculino, pois a educação física ainda hoje é tratada, ao que tudo indica, como uma divisão de métodos e conteúdos os quais reforçam a relação corpomente ${ }^{2}$ em sua prática pedagógica. Esse fato nos leva a pressupor que os professores desta disciplina não a compreendem como um todo. Sob essa análise real e atual, a construção do corpo se restringe a conhecimentos relativos à anatomia, à fisiologia, à biomecânica e à bioquímica. Isso nos parece ser um indicador para uma melhor reflexão que nos capacite a analisar, mais criticamente, as atividades que são oferecidas nas aulas de educação física. Um dos motivos para que isso ocorra é apontado por Oliveira (1984, p.67) quando o autor expõe que "encarada a Educação Física essencialmente sob o seu aspecto biológico, o professor fica reduzido simplesmente a um educador do físico". O que nos leva a inferir que as questões de cunho sociocultural não são exploradas, quer entre os docentes e seus pupilos em qualquer nível de escolaridade, do fundamental ao superior.

O gênero no espaço escolar não se inscreve apenas em por(3) Grifo nosso tas de banheiro, de muros e de paredes. Ele "invade"3 a escola por meio das atitudes dos alunos em sala de aula, na convivência social entre eles e, ainda, é reproduzido nas disciplinas de formação do profissional de educação física. É nas aulas de educação 
física que percebemos a delimitação desse conhecimento quando o professor aborda o corpo do seu aluno. Quem já deixou de ouvir frases como: "homem não chora!", "menino não brinca de roda!" ou ainda "homem não dança!" ${ }^{4}$ ! Nesses casos, é fundamental que se questione o modelo de eficiência que tem servido como parâmetro de referência às atividades ditas femininas ou masculinas.

O que se observa, é que outros saberes, não menos relevantes, como a formação sociocultural de nossos alunos, são, aparentemente, dispensáveis nestas aulas ou quando discutidos, os são abordados superficialmente, contrariando o pensamento de Daolio (1995) quando afirma que o corpo sofre uma construção cultural. Este pensamento encontra apoio em Scott (1995) e igualmente é corroborado por Romero (1995) quando as pesquisadoras reforçam o aspecto cultural na "arquitetura" do corpo masculino e do corpo feminino. Essa temática gênero/corpo é uma questão que paira, também, acerca das aulas de educação física e, até o presente, ainda tem tido discussões e resultados incipientes por parte de professores responsáveis por esta disciplina ${ }^{5}$. Essas discussões, presentes no universo da cultura corporal de movimento, dizem respeito à configuração de padrões de gênero masculino e feminino e sua relação com corpo e com a motricidade. Padrões esses, que se constroem e são cultivados desde nosso nascimento, pautados em referências biológicas e socioculturais.

O que realmente observamos hoje é que cada vez mais o corpo é privilegiado apenas como uma estrutura biológica. A construção social e o apelo ao consumo estético nas relações de gênero podem ser compreendidos pela explicitação das atitudes cotidianas, muitas vezes automáticas e inconscientes, com referências em valores preconceituosos. Nas aulas de educação física, esses aspectos relacionando o gênero, nos quais constitui uma "[...] categoria social imposta sobre um corpo sexuado [...]" (SCOTT, 1995, p.75), que são percebidos com mais clareza nos relacionamentos dos alunos entre si, quando se formam grupos predeterminados, os quais são chamados "Clube da Luluzinha" e "Clube do Bolinha", passando pelas amizades "exclusivas" mesmo sexo) até chegar aos valores preconceituosos. Para Abreu (1995), é nas aulas de educação física que ocorre a persistência de antigos estereótipos ligados ao gênero como a separação sexual entre práticas esportivas e de lazer dirigidas às meninas e aos
(4)- Essas expressões são natural e comumente utilizadas nas aulas de educação física no que concerne à construção do corpo masculino.

(5) Nas últimas décadas a questão gênero só conseguiu atingir efetivamente o universo das ciências sociais e humanas. Nesse sentido, acreditamos que a Educação Física carece de estudos acerca de gênero ou de investigações em que a referencie a interdisciplinariedade com esses objetos de estudo. Para melhores esclarecimentos, sugerimos a leitura de Abreu (1995), Romero (1995) e Rosemberg (1995) 
(7) Para este assunto, é imprescindível a leitura do estudo da profa. Leila Mello (2001), que versou sobre Gênero e suas implicações na corporeidade e motricidade em alunos do $1^{\circ}$ ciclo de formação do ensino fundamental.

(8) Pela sua contemporaneidade e abrangência, sugerimos o estudo da Profa. Elaine Romero acerca dos "Estereótipos masculinos femininos em professores de Educação Física" (1990), cujo propósito foi analisar a presença de estereótipos sexuais nos adjetivos sobre os quais os (as) professores (as) julgavam adequados para ao sexo masculino e para o sexo feminino.

(9) Nesse contexto, entendemos por dicotomia, a divisão do Ser do Homem oriundo do dualismo psicofísico de Platão, do modelo cartesiano de Descartes e da crise das Ciências no positivismo. meninos ${ }^{7}$, ou ainda, na discriminação sofrida por eles nas escolhas de atividades ditas "masculinas". Essa visão acerca da construção do corpo ainda está permeada por valores culturais, estabelecendo padrões de identificação para a caracterização de gênero em relação à motricidade. Nesse entendimento, características como força e velocidade são comumente encontradas nos meninos, enquanto a expressão oral e a motricidade fina nas meninas. Desde tenra idade, meninos e meninas seguem modelos que, para Scott (op.cit.) são historicosociais e que tendem a favorecer as expectativas dos pais, dos vizinhos, de parentes ou de amigos.

Nessa perspectiva, o modelo reproduzido nas práticas esportivas, lúdicas ou recreativas favorece à formação de estereótipos ${ }^{8}$, de preconceitos ou de discriminação, que serão incorporados dentro e fora do contexto escolar. Sendo assim, percebemos que a construção cultural do corpo masculino nas aulas de educação física é fruto dos valores e dos conceitos impostos e persistentes normas e condutas sociohistóricas que interferem na construção do corpo masculino e do corpo feminino. Neste estudo, presumimos que esses aspectos relacionados às "arquiteturas", às relações, às práticas e às representações de corpos têm fundo sociohistórico e cultural. Percebemos ainda, que a sociedade estabelece normas, padrões de comportamento e de atitudes próprias para cada sexo.

Desta forma, os valores estabelecidos e mantidos pelos agentes socializadores reforçam a diferença entre os sexos. Isso enseja o fortalecimento e a assimilação de papéis culturalmente sexuados e dificulta a compreensão do possível rompimento da submissão de um corpo (sexo) pelo outro.

Sabendo de antemão que este corpo reflete as conseqüências do dualismo psicofísico e da relação dicotômica ${ }^{9}$ : corpo-mente e das suas profundas raízes oriundas da escola, da igreja e da família, as presentes idéias se propõem a um contributo no sentido de estabelecer no contexto da Educação Física, uma interpretação cultural de corporeidade e de motricidade, que transformamos em objeto teórico formal de estudo. Ora, se desde cedo reforçamos esses tipos de conceitos e valores, como podemos falar de uma Educação para a vida? E o que é feito para o exercício da cidadania? E quanto às realidades sociais? Como podemos falar de Educação quando nossa formação ainda é fundamentada em concepções estereotipadas? Essa concepção, superficialmente abordada pelos alunos e professores de educação física, sugere que venhamos a 
refletir o tema gênero em sua totalidade, pois estar atento a isso, é uma forma de ajudar os alunos na construção do gênero com o equilíbrio e consciência dentro e fora da escola.

\section{O caminho trilhado}

Este estudo está inserido no paradigma fenomenológicohermenêutico, utilizando como estratégia da análise de discurso. Os atores sociais escolhidos foram 27 alunos de graduação em educação física, selecionados aleatoriamente, entre as principais universidades públicas e particulares do Estado do Rio de Janeiro. Sendo 6 da Universidade Federal Rural do Rio de Janeiro, 7 da Universidade Federal do Rio de Janeiro, 7 Universidade Estácio de Sá e 7 Universidade Salgado de Oliveira/ Niterói. O instrumento empregado foi uma entrevista semi-estruturada, compreendendo cinco questões que versavam sobre as diferentes percepções de construção do corpo masculino na disciplina de educação física. Esta entrevista contou com a exibição de uma foto de bailarinos do sexo masculino pousando com tutu - vestimenta tradicional e comumente utilizada pelo sexo feminino (figura a seguir). Essa estratégia serviu como uma forte aliada na estratégia de impacto com os atores sociais da pesquisa e, a partir daí, pudemos identificar e analisar a percepção que os participantes apresentavam da foto e dos propósitos da nossa pesquisa.

\section{Incursionando nos discursos}

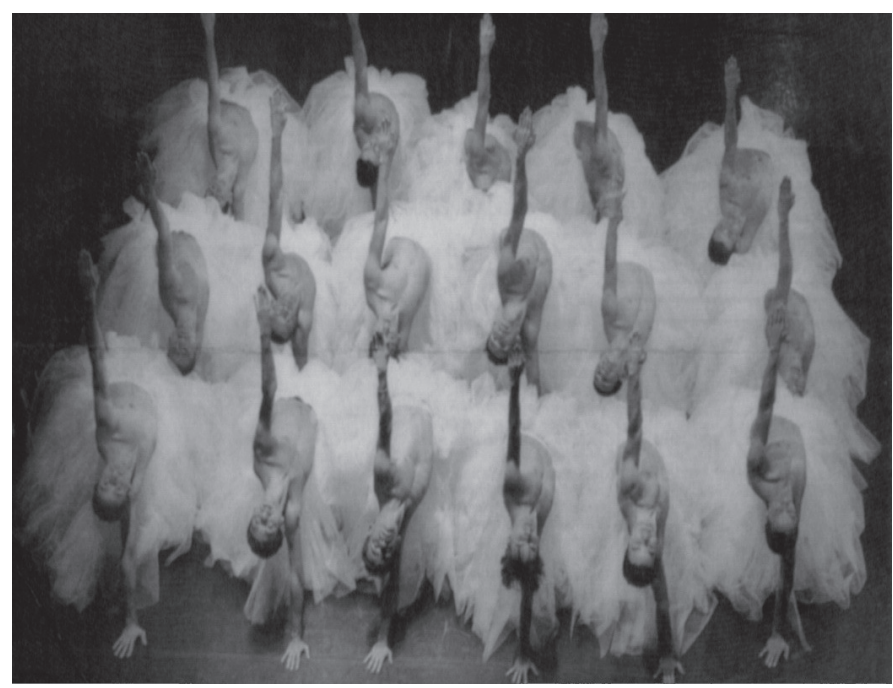


A partir da apresentação desta foto, como elemento integrante do instrumento da pesquisa, tomamos os depoimentos dos entrevistados.

Colhidos os dados, apreciamos os discursos dos Atores Sociais (AS) da nossa investigação e verificamos a presença constante de seis elementos nas falas dos mesmos. Fato esse que se tornou muito interessante, pois esses elementos, muito embora as questões tivessem metas diferentes, aparecem de forma marcante em todos os discursos. Isso nos deixa bastante à vontade para apresentar e discutir os elementos tais como se apresentam e não como comumente deveriam ser comentados - seguindo as questões postas. Sendo assim, os elementos identificados foram assim classificados:

Vestimenta: um símbolo

Através das falas dos Atores Sociais (AS), percebemos que a vestimenta/roupa utilizada pelos bailarinos foi motivo de um impacto que nos levou a colocá-lo como destaque. Nesse entendimento, na questão 1 "Qual é a impressão que você tem dessa foto?" e na questão 2 "Você acredita que essa atividade está de acordo com o sexo masculino? Por que?", foram destacados os discursos mais significantes: Segundo Pedro "é uma coisa meio estranha [...] com umas roupas estranhas[...]"; já parta Lucas " porque é difícil homem usar saia para dançar balé, é meio forçasão de barra". Para Joaquim, "[...] a única diferença só é que os caras poderiam tá com uma roupa diferente

[...] saia é coisa pra mulher, nada a ver com o macho [...]" . Nossa interpretação clarifica essa idéia de "surpresa", quando o Alberto exprime que "uma impressão assim espantosa A gente [pausa]..... Não é comum de ver um grupo de homens dançando com esse tipo de roupa [...]". Em nossas análises, as vestimentas puderam nos fornecer com clareza informações bastante detalhadas, especialmente no caso de símbolos e trajes associados a grupos sociais particulares, e o quão asseados, vivamente impactante e sutis eles são.

Nesse entendimento, podemos concluir, então, que existe uma forte relação entre o símbolo da vestimenta e o discurso dos Atores Sociais. Essa relação pode ser compreendida quando a vestimenta/roupa é uma marca registrada que tem o poder de distinguir o indivíduo do grupo ou, ainda, o grupo de um outro grupo ao qual eles pertencem. 
As atividades ditas masculinas versus atividades ditas femininas: um discurso sobre a masculinidade

Atendendo a expectativas da nossa sociedade patriarcal e sexista, Danilo ao ser questionado sobre "Você acredita que essa atividade está de acordo com o sexo masculino? Por que?", destaca que "Bem [risos], não deixo as minhas sobrinhas brincar com brinquedos que não sejam para garota. Sei lá! Parece que pode influenciar mais tarde". Mais adiante, Danilo enfatiza "[...] não tenho preconceito, mas por que o homem tem que brincar de casinha? E por quê a garota tem que jogar bola? Já está na nossa cultura - o futebol pra meninos e pra meninas, a queimada".

Podemos interpretar, então, que esses (pre) conceitos tão comuns em nosso cotidiano, expressam, na verdade, estereótipos sobre a masculinidade e feminilidade. Essas visões são heranças culturais transmitidas e reforçadas pela sociedade representada pela família, amigos, vizinhos e pela própria escola.

Observamos esse fato na fala de Antônio, quando questionado sobre "Qual a relacão da danca e a masculinidade/ virilidade?", expressa atentamente: "Ah! Existe, acho que Pô [...], têm pessoas que gosta né? Cara, tem o dom de dançar, sei lá! Tem outros que não têm". E a masculinidade e a feminilidade? "Sei lá, não sei como te explicar isso. Masculinidade, pô! Sei lá. Acho que essa dança aqui é mais pô! [...] pra mulher, né?" Mas você tem noção do que seja masculinidade? "É isso aí que não sei explicar, mas tem a ver em ser macho. O cara para ser macho não pode negar fogo, tem que ser viril. Então não tem nada a ver com a dança: que tem ser suave, frágil, leve e 'jeitosinho'". Sobre a mesma pergunta, Caio confirma "A relação entre a dança e a masculinidade? Acho que não tem relação não [risos]". Nenhuma relacão? "Nenhuma. Porque a dança propriamente dita, como eu falei no começo, a dança propriamente dita é uma prática feminina". É? "É". Então o homem que for praticar a danca pode ter sua masculinidade ou virilidade posta à prova? "Não sei se a masculinidade, mas com certeza, geral vai olhar diferente pra o cara". Mas por quê? "Porque não é comum homem fazer dança. Quando ele pratica, ele é diferente". Diferente como? "Sei lá [...], ele é mais afeminado, com jeitinho de garotinha [com uma voz de deboche]. E todo mundo zoa mesmo, nem que seja por trás, zoa". Você zoa também? "De vez em quando, né". Percebemos nesses discursos mencionados, a existência de uma con- 
fusão conceitual. A masculinidade não se apresenta de modo uniforme, destacando-se a existência de padrões hegemônicos e outros subordinados a estes. Tais formas baseiam-se no poder social dos homens, sendo estas assumidas de modo complexo por homens individuais. A hegemonia é uma forma de dominação em que o dominado participa da dominação. No campo de gênero, trata-se da capacidade de impor uma definição específica sobre outros tipos de masculinidade, o que significa que o modelo exaltado corresponde, na realidade, aquele que pode ser atribuído a poucos homens (CONNELL, 1995).

Futebol: a paixão do brasileiro e dos nossos atores

$\mathrm{Na}$ questão 3 "Se você fosse convidado a praticar danca (clássica/ moderna) você aceitaria?", encontramos respostas como as do Pedro que explica: "Porque eu não gosto de ballet, sapateado esses negócios [...]". Esse negócio o que? "Ballet, dança, coisa de mulher. Eu não gosto disso". Mas, porque não gosta? "Porque não gosto. Porque sou homem [risos!]. Gosto mais de futebol, de artes marciais, coisas que trabalhem força, resistência e agilidade. [...]. Mas geralmente o homem que faz ballet, é mal visto, [...] Sabia?" Como assim? "Não, eu não gosto, nunca gostei de dança, nem dançar em boate assim eu gosto. Dança [...]. Nem dançar em boate eu danço assim".

Já na questão 2 "Você acredita que essa atividade está de acordo com o sexo masculino?", Antônio revela que "Própria para o sexo masculino, não [...]. Você percebe alguma diferenca? "Não, sendo para o sexo masculino, mas tem gente que gosta por exemplo da dança, aqui no caso o ballet, mas eu não praticaria, por uma questão de gosto, de sexualidade [risos], mas é uma arte. Pro sexo feminino". Você acha que a danca não é para o sexo masculino? "Não, a dança sim, mas o ballet [...] também não sei não [....], mas tem uns que se destacam, gosta por exemplo é[... a percentagem de homem gostar de dança hoje em dia tá cada vez aumentando". Você não acha que essa posicão seja fruto de um [...]. Qual a origem desse pensamento? "[... É. É porque, o homem tem mais o apego pelas [...] atividades vamos dizer assim, mais ditas masculinas como futebol, pelo judô, onde já, desde pequeno somos estimulados a jogar bola. Ah! Nossa cultura mesmo influi muito sobre isso. O futebol é o esporte do Brasil, todo homem gosta, dificilmente um homem não gosta“. Caio 
concorda com Antônio quando exprime a idéia de "Própria não". Porque? "Porque foi como o Márcio [um amigo que estava ao seu lado observando atentamente e que também participara da entrevista] falou a cultura brasileira não é essa". Porque você não acha que seja própria para o sexo masculino? "Por isso. Porque a cultura brasileira. Não [...] porque tipo, você compara o ballet com o futebol. [...] Então você compara o ballet com o futebol não é a mesma coisa: de 100 alunos de ballet 10 são homens, entendeu por aí pelo menos e no futebol e o contrário". E você acha que o que leva a isso, ao pessoal tem mais tendência, os homens tem mais tendências a atividades ditas masculinas, é o que você acha que leva a isso? "A [...] masculinidade né! Como posso dizer é [...] fugiu agora palavra. É [...]" Isso tem alguma coisa haver com cultura? "Não. Acho que [...] o homem em si não, o homem, homem mesmo em si não vai escolher ballet como uma atividade física". Mas será que as pessoas lá da Rússia - país de tradicão com essas atividades físicas - não teria uma tendência cultural? "Agora você me pegou [...]. Mas não acho que seja cultural e sim da espécie masculina. Nenhum homem, independente de sua cultura, vai preferir dança do que o esporte mais praticado do mundo que o nosso futebol".

Os "outros"

Encontramos na questão 3: "Se você fosse convidado a praticar danca (clássica/moderna) você aceitaria? e na questão 5: "Se você tivesse um familiar mais próximo praticando danca ou que fosse convidado a sua prática, você apoiaria?", uma contradição entre as falas dos Atores Sociais. Dos vinte e sete entrevistados, apenas 4 responderam positivamente à questão 3. De primeira mão, parecia um resultado favorável, mas logo essa percepção foi esclarecida no momento do estudo e análise das respostas à $5^{\text {a }}$ questão: desses mesmos quatro respondentes, acenaram negativamente sobre a prática da dança por um parente mais próximo. Esse fato poderia ter passado desapercebido, se esses quatro não tivessem em suas respostas 3 aspectos comuns: 1- eram do sexo feminino; 2- responderam positivamente à $3^{\mathrm{a}}$ questão, e, na $5^{\mathrm{a}}$ questão, responderam negativamente, contrariando todas as nossas idéias preliminares; e 3na totalidade das respostas, as falas apontavam para um único 
tema: os outros. Juliana, quando questionada sobre seu possível convite à prática da dança, responde positivamente. No entanto, quando argumentada sobre o seu parente praticando esse tipo de atividade muda o discurso: "é esquisito, não consigo ver meu tio ou sobrinho fazendo dança, ainda mais com esses trajes. Eles não têm afinidades físicas e morais com essas coisas, eles são lutadores de Jiu-Jitsu. Não tem nada a ver com eles". Mas por quê? "Ah! Talvez minha família não entenderia. Minha família é muito conservadora. E eu ficaria com medo do que os meus amigos e vizinhos poderiam pensar [risos]".As palavras de Patrícia vão além: "comigo tudo bem, mas meu irmão não aceitaria, mesmo. É coisa para mulher". Por quê? "Porque lida com a sutileza, com movimentos leves, femininos e graciosos, que homem não tem [...] e eu tenho medo do que os outros podem pensar do meu irmão". Luciana revela que "os meus amigos iriam rir da minha cara [...]". Segundo Érika, "[...] meus amigos tudo bem, mas meu irmão, eu não apoiaria". Por que não? "Fica difícil aceitar um irmão fazer dança ou ballet, pois as pessoas iriam desconfiar de sua honra". Masculinidade? "É".

Fica clara e explícita a importância que é examinada nas representações dos outros dentro das atitudes e comportamentos esperados por seu contexto social, cultural e histórico, representados aqui pelos discursos dos amigos, dos vizinhos e dos parentes/família. As reações dos outros constituíram uma das fontes mais importantes das nossas abstrações. Descobrimos como os outros influenciaram o modo de vermos o mundo e em parte aceitamos sua opinião sobre nós. Esta é a teoria do "espelho" relativa ao self - para nos ver, tratamos de observar como estamos refletimos nas reações dos outros. Além, disso, o (s) outro (s), "pode, voluntariamente ou não, interpretar todas as minhas possíveis ações como indicadoras de uma hipótese pré-concebida" (LAING, PHILLIPSON e LEE, 1974, p. 26).

Desvio social versus desvio sexual: a homossexualidade

Para alguns Atores Sociais (AS), a foto que representava homens de tutu era traduzida como: "Um monte de gay dançando" (Edvaldo). Para Samuel, numa tentativa de desconversar, reafirma que "[...], não querendo ser preconceituoso, mas eu acho que [...] há uma grande procura nessa atividade de homossexuais, de gays". Elias demonstra que "É meio complicado até porque parece que 
isso aqui é um ballet, né? É um ballet masculino, eu acredito que não tem [...] não discrimino ninguém, mas não acho legal isso aqui para homem não. Acho que, [...], sei lá não tem uma impressão uma boa pra homem". Antônio também corrobora com essa idéia afirmando que "[...] Acho que essa dança aqui é mais pô! Para a mulher, [...]. O cara para ser macho não pode negar fogo, tem que ser viril. Então não tem nada a ver com a dança: que tem ser suave, frágil, leve e 'jeitosinho'[...]". Na concepção de Caio "[...] a dança propriamente dita é uma prática feminina. [...], mas com certeza, geral vai olhar diferente pra o cara. [...] o é comum homem fazer dança. Quando ele pratica, ele é diferente. [...] ele é mais afeminado, com jeitinho de garotinha (com voz de deboche). E todo mundo zoa mesmo, nem que seja por trás, zoa $[\ldots]^{\prime}$.

Essas são algumas falas dos entrevistados que, independente do enunciado da questão, nos levou a discutir esse polêmico tema. Mas, antes de abordá-lo, paira uma pergunta: o que levou os Atores Sociais a relacionar a atividade exposta com a homossexualidade?

Raça? gênero: um universo de preconceito

O outro elemento que foi desvelado nos discursos dizia respeito à questão étnica, cujo teor nos sensibilizou pelo tom de denúncia. "Com certeza, sem problema nenhum. Não tem nem porque eu ter preconceito, pô! Eu sei que é isso cara, pô! É horrível essa parada". Porque? "O fato de ser negro". É? "Bastante. No esporte você vê isso? Pô! Quando eu jogava, um pouco". Jogou o que? "Basquete". Ah é?! "Há trinta anos atrás (com tom de brincadeira e bem a vontade!) tinha mais pessoas negras também aí normal (sic), mas colégio sempre estudei em colégio particular [...] Então vamos dizer assim [...] que você esteja um pouco mais adaptado a esse tipo de preconceito né! Se a pessoa falar que não tem preconceito hoje em dia é mentira. Tem e sempre vai ter, sempre vai ter cara, pô! Na faculdade você pode ver tem pouquíssimas pessoas negras; as poucas pessoas negras que tem são homens que praticam esportes, tem bolsa. Pô! Colégio particular, sempre estudei em colégio particular a minoria era negra cinco pessoas no máximo". Você acha que esse fato decorre em funcão de que? "Vem em função de que toda essa problemática? Do sistema cultural, do social, econômico e político [...]".

Essa foi resposta de Diogo - um rapaz negro que sofre na "pele" as conseqüências do preconceito racial - à 5 a questão "Se 
você tivesse um familiar mais próximo praticando dança o que fosse convidado a sua prática você apoiaria?". Esse depoimento nos leva a crer que o conceito de uma sociedade pluricultural, com convivência harmoniosa entre negros, brancos, mulheres e homens demostra apenas o retrato "oficioso"1 0 do Brasil.

Em uma análise de nossa realidade - e mais precisamente nos discursos de nossos atores - constatamos a presença marcante de um fator de segregação social: o preconceito - não declarado, mas operando na clandestinidade, como uma entidade presa a uma teia invisível das relações de poder, mas inserido na ideologia da sociedade. Preconceito que determina oposições conflituosas como negros, brancos, homens e mulheres, mas que a história oficial não registra como presente nas inter-relações sociais manipulando os fatos com uma dimensão ideológica significativa: o branqueamento da população brasileira e o domínio do mundo público e privado do pensamento racista, machista, patriarcal e sexista. Historicamente, registramos dificuldade para se lidar com a temática do preconceito racial, sexual e social. Nos discursos dos Atores Sociais, muitas vezes, houve manifestações de racismo, discriminação social e étnica, ainda que de maneira involuntária, inconsciente e debochada. Essas atitudes representam, ao que tudo indica, a violação dos direitos dos discriminados, trazendo consigo obstáculos ao processo nas relações sociais, pelo sofrimento e constrangimento a que esses indivíduos se vêem ou poderão passar.

As principais impressões conclusivas

Este estudo sobre a percepção de alunos de educação física acerca da construção cultural do corpo masculino, em face do que foi exposto nas considerações iniciais, no caminho trilhado, no desvelamento dos dados, e com suporte nos estudos apontados pela literatura nacional e internacional, destacou que os dados evidenciam a persistência determinante de normas, crenças, tabus, estereótipos e valores socioculturais que interferem na construção do corpo masculino. A pesquisa confirma que aspectos relacionados às "arquiteturas" das relações de gênero têm fundos socioculturais e históricas (SCOTT, 1995). Destarte, respondendo à questão norteadora da presente investigação somos levados a inferir que a educação física, ao que tudo indica, vem atuando como legitimadora e reprodutora de uma ideologia hegemônica, sexista, 
patriarcal e machista, sedimentando o "status quo". Assim considerando, podemos sublinhar que os modelos de corpo e as práticas da educação física expressos na ginástica, na dança, nos esportes ditos femininos e nos ditos masculinos entre outros, ainda são tratados como atividades meramente práticas e desprovidas de qualquer fundamentação teórica que aborde a questão sociocultural e histórica. Presenciamos, ainda, a influência do paradigma biológico, do sexismo e de estereótipos sexistas presentes nos discursos dos entrevistados, o que contribui no conjunto de mecanismos que auxiliam e reforçam a construção sociocultural e histórica dos corpos; no caso presente - o corpo masculino.

Constatamos que essas percepções, além de não contribuírem para o desenvolvimento de uma cultura corporal de movimento, limitam os movimentos corporais presentes no cotidiano dos alunos de graduação em educação física. Com base nessas inferências, propomos uma reflexão relativa às representações e relações de gênero dentro do corpo docente com a finalidade de propagar entre o corpo discente sobre essas questões. No que tange à percepção dos alunos de educação física em relação à discriminação de atividades físicas segundo o sexo deduzimos que, para os alunos entrevistados, existem alguns (pre) conceitos concernentes à prática de atividades físicas ditas femininas e que sejam freqüentadas pelos homens. Isso nos leva a crer que existe uma educação diferenciada que os indivíduos do sexo masculino recebem e levam à valorização de atitudes que condizem com o comportamento masculino esperado pela sociedade. Incursionando nas respostas dos entrevistados, observamos que a sociedade estabelece normas, padrões de comportamento e de atitudes próprias para cada sexo. Desta forma, os valores estabelecidos e mantidos pelos agentes socializadores reforçam a diferença entre os sexos. Isso enseja o fortalecimento e a assimilação de papéis culturalmente sexuados e dificulta a compreensão do possível rompimento da submissão de um sexo pelo outro. Essa concepção, superficialmente abordada pelos alunos e, provavelmente os futuros professores de educação física, sugere que venhamos a refletir o tema gênero em sua totalidade, pois estar atento a isso, é uma forma de ajudar os alunos na construção do gênero com o equilíbrio dentro e fora da escola1 1. Isso requer uma (re) leitura dos currículos dos cursos de graduação em educação física, através de seminários, palestras, encontros e outros para re- 
fletir a questão em cena em sua totalidade. Partindo desta ótica, procuramos entender como se encontra a formação do corpo masculino nas aulas de educação física, quando a escola é, ainda, segundo os escritos a continuidade do modelo de re (produção) das construções das relações de gênero tradicionais, oriundos da cultura patriarcal, sexista e machista (ROSEMBERG, 1995; ROMERO, 1995 e 1997; ALMEIDA, 2000; APPLE, 1987; BOURDIEU, 1995 e SCOTT, 1995). Percebemos, ainda, que o mundo contemporâneo não comporta mais esse elemento masculino. Ele foi destronado porque a mulher se profissionalizou, conquistou espaços sociais, políticos e esportivos e foi durante muito tempo objeto de discussões. O homem tradicional não pode mais subsistir de modo pleno e integral; esse homem emergente de corpo amaciado, que usa camisa cor de rosa, leva o filho para a escola e participa de sua educação e, além disso, tem uma sexualidade diferente também. Muitas vezes as pessoas duvidam de sua masculinidade. Esse é o novo homem que está sob suspeita e admiração, mas necessita ser analisado e discutido com o devido aprofundamento.

\section{Referências}

ABREU, Neíse Gaudêncio. Análise das percepções de docentes e discentes sobre turmas mistas e separadas por sexo nas aulas de Educação Física escolar. In: ROMERO, (Org.) Corpo, mulher e sociedade. Campinas: Papirus, 1995. p. 157-176.

ALMEIDA, Marlíse. Dimensões da masculinidade no Brasil. Cadernos do núcleo transdisciplinar de estudos de gênero- NUTEG. Niterói/RJ: EDUFF, v. 1, p.29-38, 2000.

APLLE, Michael W. Relações de classe e de gênero e modificações no processo do trabalho docente. Cadernos de Pesquisa, São Paulo, n. ${ }^{\circ}$ 60, p.3-14, fev., 1987.

AZEVEDO, Tania. A mulher na educação física e no esporte. In: ROMERO, (Org.) Mulheres em movimento. Vitória: EDUFES, 1997. p.113136.

BOURDIEU, Pierre. A dominação masculina. Educação e Realidade. Porto Alegre, vol. 20, n. ${ }^{\circ}$ 2, p. 133-184, jul./dez., 1995.

CONNELL. Robert. Políticas da masculinidade. In: Educação e Realidade. Porto Alegre, vol. 20, n. ${ }^{\circ}$ 2, p. 184-206, jul./dez, 1995.

CUNHA JÚNIOR, Carlos Fernando. Gênero e história: apontamentos de uma pesquisa sobre a masculinidade e Educação Física. Anais do 
VII Congresso Brasileiro de História da Educação Física, Esporte, Lazer e dança. Gramado, 2000. p. 396-400.

DAOLIO, Jocimar. A construção do corpo feminino ou o risco de se transformar meninas em "antas". In: ROMERO, (Org.) Corpo, mulher e sociedade. Campinas: Papirus, 1995. p.99-108.

GUEDES, Simoni Lahud. O futebol brasileiro: instituição zero. Rio de Janeiro. 1977. 175p. Dissertação (Mestrado em Antropologia Social) Programa de Pós-Graduação em Antropologia Social do Museu Nacional da Universidade Federal do Rio de Janeiro. 1977.

Jogo de corpo: um estudo de construção social de trabalhadores. 1992. 454 p. 2 v. Tese (Doutorado em Antropologia Social) - Programa de Pós-Graduação em Antropologia Social do Museu Nacional da Universidade Federal do Rio de Janeiro, 1992.

O Brasil no campo de futebol: estudos antropológicos sobre os significados do futebol brasileiro. Niterói: EDUFF, 1998.

LAING, R, PHILlipson, H. e LEE, A. Percepção interpessoal. Rio de janeiro: Eldorado, 1974.

MacDONALD, Daune. Conhecimento, gênero e proletarização na formação do professor de educação física. In: ROMERO, Elaine (Org.) Corpo, mulher e sociedade. Campinas: Papirus, 1995. p. 205-234.

MELLO, Leila. Gênero e suas implicações na corporeidade e motricidade em alunos do $1^{\circ}$ ciclo do ensino fundamental. Rio de Janeiro, 2001. Dissertação (Mestrado em Ciência da Motricidade Humana)- Programa de Pós-Graduação Stricto-Sensu em Ciência da Motricidade Humana da Universidade Castelo Branco. 180 p.

MESSNER, Michael A. e SABO, Donald F. (Editors). Sports, men and gender order: Critical feminist perspectives. Champain: Human Kinetics, 1990 .

OLIVEIRA. Vitor Marinho de. O que é educação física. São Paulo: Brasiliense, 1984.

ROMERO, Elaine. Estereótipos masculinos e femininos em professores de Educação Física. 1990. 407 p. Tese (Doutorado em Psicologia), Instituto de Psicologia, Universidade de São Paulo, São Paulo. 1990.

O corpo no século XVIII: elementos para a compreensão das atividades corporais e redimensionamento de uma práxis na passagem para o $3^{\circ}$ milênio. In: A arquitetura do corpo feminino a produção do conhecimento In: ROMERO, (Org.) Corpo, mulher e sociedade. Campinas: Papirus, 1995. p. 235-270.

ROMERO, Lahiry Silva. Corpo, espelho da vida. In: ROMERO (Org.), Mulheres em movimento. Vitória: EDUFES, 1997. p.81-88.

ROSEMBERG, Fúlvia. A educação física, os esportes e as mulheres: balanço da bibliografia brasileira. In: ROMERO, (Org.). Corpo, mulher e sociedade. Campinas: Papirus, 1995. p. 271-307. 
SCOTT, Joan. Gênero: uma categoria útil de análise histórica. Educação e Realidade, Porto Alegre, vol. 20, n. ${ }^{\circ}$ 2, p.71-99, jul./dez., 1995. 